\title{
Uji Fungsi Dan Karakterisasi Pompa Roda Gigi
}

\author{
Wismanto Setyadi, Asmawi, Masyhudi, Basori \\ Program Studi Teknik Mesin, Fakultas Teknik dan Sains, Universitas Nasional Jakarta \\ Korespondensi: tmesin@yahoo.com
}

\begin{abstract}
ABSTRAK. Pompa roda gigi merupakan pompa perpindahan positif yang tergolong dalam pompa rotari. Pompa roda gigi digunakan untuk memompa flida dengan viskositas tinggi dan sering diaplikasikan pada sistem hidrolik. Pengujian pompa roda gigi bertujuan untuk Mendapatkan kesiapan fungsional dari komponen-komponen utama peralatan pengujian pompa roda gigi dan mendapatkan karakterisasi pompa roda gigi terbaik, yaitu mencari hubungan tinggi kenaikan (head), daya poros pompa (P) dan efisiensi pompa sebagai fungsi kapasitas (Q). Fluida yang digunakan untuk pengujian adalah oli dengan massa jenis 855 $\mathrm{kg} / \mathrm{m}^{3}$, variasi kapasitas dilakukan dengan cara mengatur putaran pada control flow, kemudian kapasitas diukur menggunakan flow meter. Sehingga tekan hisap pompa $\left(\mathrm{P}_{\mathrm{s}}\right)$ dan tekanan dorong pompa $\left(\mathrm{P}_{\mathrm{d}}\right)$ pada pompa roda gigi dapat terukur pada vacum gauge dan pressure gauge. Motor listrik yang digunakan adalah tiga phasa dengan daya motor $\left(\mathrm{P}_{\text {motor }}\right)$ terpakai diukur dengan amperemeter dan voltmeter. Karakterisai pompa roda gigi dilakukan dengan tiga pulley dengan kecepatan pulley satu $2000 \mathrm{rpm}$, pulley dua $1700 \mathrm{rpm}$ dan pulley tiga $1100 \mathrm{rpm}$. Kesiapan uji fungsi komponen-komponen utama pada pengujian pompa roda gigi dapat berfungsi dengan baik. Meskipun ada sedikit kebocoran pada instalasi perpipaan yang masih dalam batas toleransi sebesar kurang dari $5 \%$. Efisiensi yang dihasilkan antara perbandingan daya fluida dengan daya poros pompa masing-masing diperoleh pada pulley satu pada putaran $2000 \mathrm{rpm}$ sebesar $98,44 \%$, pulley dua pada putaran $1700 \mathrm{rpm}$ sebesar $96,46 \%$ dan pulley tiga pada putaran $1100 \mathrm{rpm}$ sebesar 95,23\%.
\end{abstract}

Kata kunci : pompa roda gigi, uji fungsi,karakterisasi pompa, head, daya pompa, efisiensi.

\section{PENDAHULUAN}

Pada saat ini perkembangan industri sangat cepat. Banyak sekali ide-ide yang berkembang dan bermanfaat untuk masyarakat. Salah satunya adalah penggunaan pompa yang berfungsi sebagai mesin pemindah fluida dari suatu tempat yang rendah ke tempat yang lebih tinggi, atau dari suatu tempat yang rendah ke tempat yang bertekanan lebih tinggi.

Pompa telah banyak digunakan orang sejak lama, mulai dari unit terkecil di rumah tangga sampai industri-industri besar. Penggunaan pompa yang semakin luas dari waktu ke waktu menyebabkan perkembangan pompa sangat pesat. Pada era sekarang ini berbagai macam bentuk pompa dengan berbagai keunggulannya telah banyak ditawarkan oleh perusahaan-perusahaan produsen pompa.

Sering kali suatu perusahaan membuat pompa tertentu yang hanya digunakan untuk aplikasi khusus. Mengingat banyaknya jenis pompa di pasaran, maka kejelian dalam memilih pompa menjadi syarat utama agar diperoleh kerja pompa yang optimum sesuai dengan sistem yang dilayani. Pada dasarnya saat pompa bergerak, mengalami dua fungsi utama yaitu, (1) Pompa menciptakan kondisi vakum pada saluran masuk pompa, kondisi vakum mendorong fluida dari tangki ke dalam pompa yang disebabkan oleh tekanan atmosphere, (2) Gerakan mekanik pompa mengisap fluida ke dalam rongga pemompaan dan mengalirkanya keluar melalui saluarn keluar pompa.

\section{DASAR ANALISIS}

Dari data pengujian pompa roda gigi pada tabel 1, tabel 2, tabel 3, maka untuk mendapatkan data yang lebih lengkap tentang karakteristik pompa roda gigi, data percobaan tersebut harus diolah lebih lanjut sehingga menjadi data yang dapat mewakili karakteristik pompa roda gigi. Variabelvariabel yang dihitung antara lain :

- Head total pompa 


$$
H=\frac{p_{\text {out }}-p_{\text {in }}}{\gamma}
$$

Dimana: $p_{\text {out }}$ : Tekanan pada sisi dorong pompa $\left(\mathrm{N} / \mathrm{m}^{2}\right)$, pin : Tekanan pada sisi hisap pompa $\left(\mathrm{N} / \mathrm{m}^{2}\right), \gamma$ : Berat jenis fluida $\left(855 \mathrm{~kg} / \mathrm{m}^{3}\right)$

- Daya motor

$$
\mathrm{P}_{\text {motor }}=\mathrm{V} . \mathrm{I}
$$

Dimana: V : Tegangan listrik aktual pada motor penggerak (Volt), I : Arus listrik aktual yang mengalir pada motor penggerak

(Ampere).

- Daya efektif pompa

$$
P_{e p}=\frac{\eta_{\text {transmisi. }} P_{\text {rotor }}}{(1+\alpha)}
$$

Dimana : Protor : Daya rotor (watt), $\eta$ transmisi : Efisiensi transmisi, $\eta:$ Faktor cadangan.

- Daya fliuda

$$
\mathrm{P}_{\text {fluida }}=\gamma \cdot \mathrm{Q} \cdot \mathrm{H}(\text { watt })
$$

$\gamma$ : Berat jenis fluida $\left(855 \mathrm{~kg} / \mathrm{m}^{3}\right)$ atau $\left(8387,55 \mathrm{~N} / \mathrm{m}^{3}\right), \rho$ : Massa jenis fluida $\left(\mathrm{kg} / \mathrm{m}^{3}\right), \mathrm{g}$ : Percepatan gravitasi $\left(9,81 \mathrm{~m}^{2} / \mathrm{s}\right), \mathrm{Q}$ : Debit fluida $\left(\mathrm{m}^{3} / \mathrm{s}\right), \mathrm{H}:$ Head total pompa $(\mathrm{m})$

- Efisiensi pompa

$$
\eta=P_{\text {fluida }} / \text { Pep } \times 100 \%
$$

Dimana: $\eta$ : Efisiensi pompa, Pfluida : Daya fluida (watt), Pep : Daya efektif pompa (watt)

- Efisiensi Mekanik

$$
\eta \text { mekanik }=\mathrm{P}_{\text {poros }} / \mathrm{P}_{\text {listrik }} \times 100 \%
$$

Dimana $: \eta$ : Efisiensi, $\mathrm{P}_{\text {poros }}$ : Daya poros (watt), $\mathrm{P}_{\text {listrik }}$ : Daya listrik (watt)

- Efisiensi Hidraulik

$$
\eta \text { hidraulik }=\mathrm{P}_{\text {fluida }} / \mathrm{P}_{\text {listrik }} \times 100 \%
$$

Dimana $: \eta$ : Efisiensi, $\mathrm{P}_{\text {fluida }}$ : Daya poros (watt), $\mathrm{P}_{\text {listrik }}$ : Daya listrik (watt)

TABEL 1. Data pengujian pompa gear pada putaran pompa $2000 \mathrm{rpm}$.

\begin{tabular}{|c|c|c|c|c|c|}
\hline No. & $\mathbf{Q}\left(\mathbf{m}^{\mathbf{3}} / \mathbf{s}\right)$ & $\mathbf{P}_{\mathbf{s}}\left(\mathbf{N} / \mathbf{m}^{\mathbf{2}}\right)$ & $\mathbf{P}_{\mathbf{d}}\left(\mathbf{N} / \mathbf{m}^{\mathbf{2}}\right)$ & $\mathbf{I}$ (ampere) & $\mathbf{v}$ (volt) \\
\hline 1 & 0 & 0 & 980665 & 2,7 & 220 \\
\hline 2 & 1,35 & 40636,656 & 784532 & 2,5 & 220 \\
\hline 3 & 1,5 & 47409,432 & 392266 & 2,2 & 220 \\
\hline 4 & 1,55 & 47409,432 & 372652,7 & 2 & 220 \\
\hline 5 & 1,56 & 47409,432 & 372652,7 & 2 & 220 \\
\hline 6 & 1,6 & 54182,208 & 353039,4 & 1,9 & 220 \\
\hline
\end{tabular}


TABEL 2. pengujian pompa gear pada putaran pompa $1700 \mathrm{rpm}$

\begin{tabular}{|c|c|c|c|c|c|}
\hline No. & $\mathbf{Q}\left(\mathbf{m}^{\mathbf{3}} / \mathbf{s}\right)$ & $\mathbf{P}_{\mathbf{s}} \mathbf{( N / \mathbf { m } ^ { \mathbf { 2 } } )}$ & $\mathbf{P}_{\mathbf{d}}\left(\mathbf{N} / \mathbf{m}^{\mathbf{2}}\right)$ & $\mathbf{I}$ (ampere) & $\mathbf{v}$ (volt) \\
\hline 1 & 0 & 3386,388 & 980665 & 2,7 & 220 \\
\hline 2 & 1,37 & 40636,656 & 784532 & 2,6 & 220 \\
\hline 3 & 1,46 & 44023,044 & 353039,4 & 2,2 & 220 \\
\hline 4 & 1,47 & 44023,044 & 353039,4 & 2,2 & 220 \\
\hline 5 & 1,5 & 44023,044 & 294199,5 & 2 & 220 \\
\hline 6 & 1,53 & 47409,432 & 294199,5 & 2 & 220 \\
\hline
\end{tabular}

TABEL 3. pengujian pompa gear pada putaran pompa $1100 \mathrm{rpm}$

\begin{tabular}{|c|c|c|c|c|c|}
\hline No. & $\left.\mathbf{Q} \mathbf{~ ( m}^{\mathbf{3}} \mathbf{/ s}\right)$ & $\mathbf{P}_{\mathbf{s}}\left(\mathbf{N} / \mathbf{m}^{\mathbf{2}}\right)$ & $\mathbf{P}_{\mathbf{d}} \mathbf{( N / \mathbf { m } ^ { 2 } )}$ & $\mathbf{I}(\mathbf{a m p e r e})$ & $\mathbf{v}(\mathbf{v o l t})$ \\
\hline 1 & 0 & 3386,388 & 980665 & 2,7 & 220 \\
\hline 2 & 1,3 & 27091,104 & 725692,1 & 2,4 & 220 \\
\hline 3 & 1,35 & 27091,104 & 490332,5 & 2,4 & 220 \\
\hline 4 & 1,38 & 27091,104 & 196133 & 2,2 & 220 \\
\hline 5 & 1,39 & 27091,104 & 156906,4 & 2,2 & 220 \\
\hline 6 & 1,41 & 27091,104 & 156906,4 & 2,2 & 220 \\
\hline
\end{tabular}

\section{Hasil dan Pembahasan Uji Fungsi}

TABEL 4. Head, Daya Pompa dan Efisiensi Pompa Roda Gigi Pada Kondisi Operasional.

\begin{tabular}{|c|c|c|c|c|}
\hline \multirow[b]{2}{*}{ Besaran Pompa } & \multirow{2}{*}{$\begin{array}{c}\text { Data } \\
\text { Spesifikasi }\end{array}$} & \multicolumn{3}{|c|}{ Data Aktual } \\
\hline & & $\begin{array}{c}\text { Pulley } 1 \\
\text { (2000 rpm) }\end{array}$ & $\begin{array}{c}\text { Pulley } 2 \\
\text { (1700 rpm) }\end{array}$ & $\begin{array}{c}\text { Pulley } 3 \\
\text { (1100 rpm) }\end{array}$ \\
\hline Kapasitas $\left(\mathrm{m}^{3} / \mathrm{s}\right)$ & 1,10 & 1,35 & 1,37 & 1,30 \\
\hline Head (m) & 90 & 88,69 & 88,69 & 83,29 \\
\hline Daya Pompa (watt) & 566 & 283,02 & 294,34 & 271,7 \\
\hline Efisiensi pompa (\%) & 80 & 98,4 & 96,4 & 95,2 \\
\hline Efisiensi mekanik (\%) & - & 51,45 & 51,45 & 51,45 \\
\hline Efisiensi hidrolik (\%) & - & 50,65 & 49,64 & 49,00 \\
\hline
\end{tabular}

\section{HASIL DAN PEMBAHASAN}

Berdasarkan tabel 4. komponen-komponen utama pada pengujian pompa roda gigi yang harus diperhatikan adalah rancang bangun rangka alat pengujian pompa roda gigi. Pada perancangan rangka menggunakan besi dengan ketebalan $4 \mathrm{~mm}$ terlalu berlebihan (over). Tetapi dengan pemilihan ketebalan tersebut, mempermudah dalam tahap pengerjaan las dan menghasilkan konstruksi rangka lebih kuat, sehingga tidak terjadi lendutan pada rangka. Hasil uji fungsi menunjukan bahwa rangka alat pengujian pompa roda gigi sesuai dengan target atau berfungsi dengan baik.

Pada instalasi perpipaan alat pengujian pompa roda gigi masih terjadi kebocoran pada beberapa titik seperti sembungan pipa dan fitting untuk pressure gauge. Kebocoran terjadi karena tekanan dari pompa yang terlalu besar dan kualitas perpipaan yang hanya menggunakan pipa PVC dan daya pengeleman yang kurang kuat. Namun kebocoran masih dalam batas toleransi di bawah 5 $\%$ dari target yang diinginkan. Instalasi kelistrikan berfungsi dan beroperasi dengan baik, namun berbanding terbalik oleh arus listrik yang tidak stabil, tetapi dengan arus listrik tersebut masih dapat untuk mengoperasikan motor listrik dan mengoperasikan pompa roda gigi. Pompa roda gigi dapat beroperasi dengan optimal sesuai dengan target yang diinginkan.

Jadi kesiapan fungsional dari hasil uji fungsi komponen-komponen utama alat pengujian pompa roda gigi sudah cukup baik, sehingga kurva karakteristik pompa roda gigi pada titik kerja optimal pompa dapat diperoleh. Sebelum melakukan pengujian pompa roda gigi, maka harus diperhatikan dahulu kesiapan fungsional dari komponen-komponen utama alat pengujian pompa roda gigi. 
Berikut ini merupakan beberapa kesiapan fungsional komponen-komponen utama dari alat pengujian pompa roda gigi yang ditunjukkan pada tabel 5 .

TABEL 5. Kesiapan fungsional komponen-komponen utama alat pengujian pompa.

\begin{tabular}{|c|c|c|c|c|}
\hline No. & Parameter & Target & Hasil Uji fungsi & Keterangan \\
\hline 1 & $\begin{array}{l}\text { Rangka Alat } \\
\text { Pengujian Pompa } \\
\text { Roda Gigi }\end{array}$ & $\begin{array}{c}\text { Pembebanan maksimum } \\
\text { rangka } 84,5 \mathrm{~kg} \text { untuk beban } \\
\text { statis }\end{array}$ & $\begin{array}{c}\text { Rangka mampu menerima } \\
\text { beban peralatan pengujian } \\
\text { pompa dengan beban statis } \\
84,5 \mathrm{~kg}\end{array}$ & $\begin{array}{l}\text { Rangka tidak } \\
\text { mengalami } \\
\text { lendutan }\end{array}$ \\
\hline 2 & Instalasi Perpipaan & $\begin{array}{l}\text { Tidak ada kebocoran pada } \\
\text { instalasi perpipaan }\end{array}$ & $\begin{array}{l}\text { Ada sedikit kebocoran } \\
\text { (kurang dari 5\%) }\end{array}$ & $\begin{array}{l}\text { Kebocoran terjadi } \\
\text { akibat tekanan } \\
\text { yang terlalu tinggi } \\
\text { pada pompa }\end{array}$ \\
\hline 3 & Instalasi Kelistrikan & $\begin{array}{c}\text { Lampu indikator dapat } \\
\text { menyala sesuai dengan } \\
\text { fungsinya }\end{array}$ & $\begin{array}{l}\text { Lampu indikator dapat } \\
\text { menyala sesuai dengan } \\
\text { fungsinya }\end{array}$ & Instalasi baik \\
\hline 4 & Motor Listrik & Daya Motor 1026 watt & Daya Motor aktual 672 watt & $\begin{array}{l}\text { Motor mampu } \\
\text { menggerakkan } \\
\text { pompa roda gigi }\end{array}$ \\
\hline 5 & Pompa Roda Gigi & $\begin{array}{c}\text { Didapat kurva karakterisasi } \\
\text { pada titik kerja optimal } \\
\text { pada kapasitas } 1,1 \mathrm{~m}^{3} / \mathrm{jam}, \\
\text { Daya } 566 \text { watt, Head } 90 \mathrm{~m} \\
\text { dan efisiensi } 80 \%\end{array}$ & $\begin{array}{l}\text { Didapat kurva karakterisasi } \\
\text { pada titik kerja optimal }\end{array}$ & $\begin{array}{l}\text { Pompa bekerja } \\
\text { optimal }\end{array}$ \\
\hline
\end{tabular}

\section{Hasil dan Pembahasan Karakterisasi Pompa Roda Gigi}

Setelah memasukan data pengujian pompa roda gigi yang berada pada tabel 1, tabel 2 dan tabel 3, ke persamaan (17), persamaan (18), persamaan (19), persamaan (20) dan persamaan (21), maka diperoleh hasil perhitungan yang menggambarkan karakterisasi pompa roda gigi, seperti tertera pada tabel 6, tabel 7 dan tabel 8 serta gambar 1, gambar 2 dan gambar 3.

TABEL 6. Hasil pengolahan data pengujian pompa gear pada putaran pompa $2000 \mathrm{rpm}$.

\begin{tabular}{|c|c|c|c|c|c|c|}
\hline No & $Q\left(\mathbf{m}^{3} / \mathbf{j a m}\right)$ & $\mathbf{H}(\mathbf{m})$ & Pporos (watt) & $\eta_{\text {pompa }}(\%)$ & $\eta_{\text {mekanik }}(\%)$ & $\eta_{\text {hidrolik }}(\%)$ \\
\hline 1 & 0 & 116,51 & 305,66 & 0 & 51,45 & 0 \\
\hline 2 & 1,37 & 88,69 & 294,34 & 96,4 & 51,45 & 49,6 \\
\hline 3 & 1,46 & 36,84 & 249,05 & 50,2 & 51,45 & 25,8 \\
\hline 4 & 1,47 & 36,84 & 249,05 & 50,6 & 51,45 & 26,0 \\
\hline 5 & 1,5 & 29,82 & 226,41 & 46,0 & 51,45 & 23,6 \\
\hline 6 & 1,53 & 29,42 & 226,41 & 46,3 & 51,45 & 23,8 \\
\hline
\end{tabular}

TABEL 7. Hasil pengolahan data pengujian pompa gear pada putaran pompa $1700 \mathrm{rpm}$.

\begin{tabular}{|c|c|c|c|c|c|c|}
\hline No & $\mathbf{Q}\left(\mathbf{m}^{\mathbf{3}} \mathbf{j} \mathbf{j a m}\right)$ & $\mathbf{H}(\mathbf{m})$ & Pporos (watt) & $\eta_{\text {pompa }}(\mathbf{\%})$ & $\eta_{\text {mekanik }}(\mathbf{\%})$ & $\boldsymbol{\eta}_{\text {hidrolik }}(\mathbf{\%})$ \\
\hline 1 & 0 & 116,91 & 305,66 & 0 & 51,45 & 0 \\
\hline 2 & 1,35 & 88,69 & 283,02 & 98,4 & 51,45 & 50,6 \\
\hline 3 & 1,5 & 41,11 & 249,05 & 58,1 & 51,45 & 29,9 \\
\hline 4 & 1,55 & 38,77 & 226,41 & 61,9 & 51,45 & 31,8 \\
\hline 5 & 1,56 & 38,77 & 226,41 & 62,1 & 51,45 & 31,9 \\
\hline 6 & 1,6 & 35,63 & 215,09 & 62,0 & 51,45 & 31,9 \\
\hline
\end{tabular}

TABEL 8. Hasil pengolahan data pengujian pompa gear pada putaran pompa $1100 \mathrm{rpm}$.

\begin{tabular}{|c|c|c|c|c|c|c|}
\hline No & $\left.\mathbf{Q} \mathbf{~ ( m}^{\mathbf{3}} / \mathbf{j a m}\right)$ & $\mathbf{H}(\mathbf{m})$ & Pporos (watt) & $\eta_{\text {pompa }} \mathbf{( \% )}$ & $\eta_{\text {mekanik }} \mathbf{( \% )}$ & $\eta_{\text {hidrolik }}(\mathbf{\%})$ \\
\hline 1 & 0 & 116,51 & 305,66 & 0 & 51,45 & 0 \\
\hline 2 & 1,3 & 83,29 & 271,7 & 95,2 & 51,45 & 49,0 \\
\hline 3 & 1,35 & 55,22 & 271,7 & 64,09 & 51,45 & 32,9 \\
\hline 4 & 1,38 & 20,15 & 249,05 & 26,10 & 51,45 & 13,4 \\
\hline 5 & 1,39 & 15,47 & 249,05 & 20,20 & 51,45 & 10,3 \\
\hline 6 & 1,41 & 15,47 & 249,05 & 20,44 & 51,45 & 10,5 \\
\hline
\end{tabular}




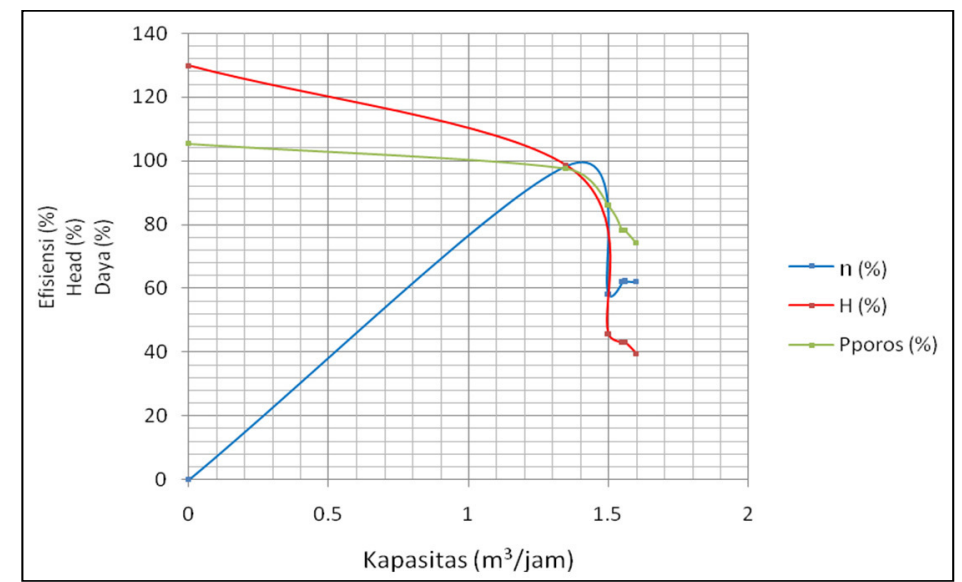

GAMBAR 1. Grafik antara efisiensi, daya pompa, head dengan kapasitas pompa pada putaran $2000 \mathrm{rpm}$.

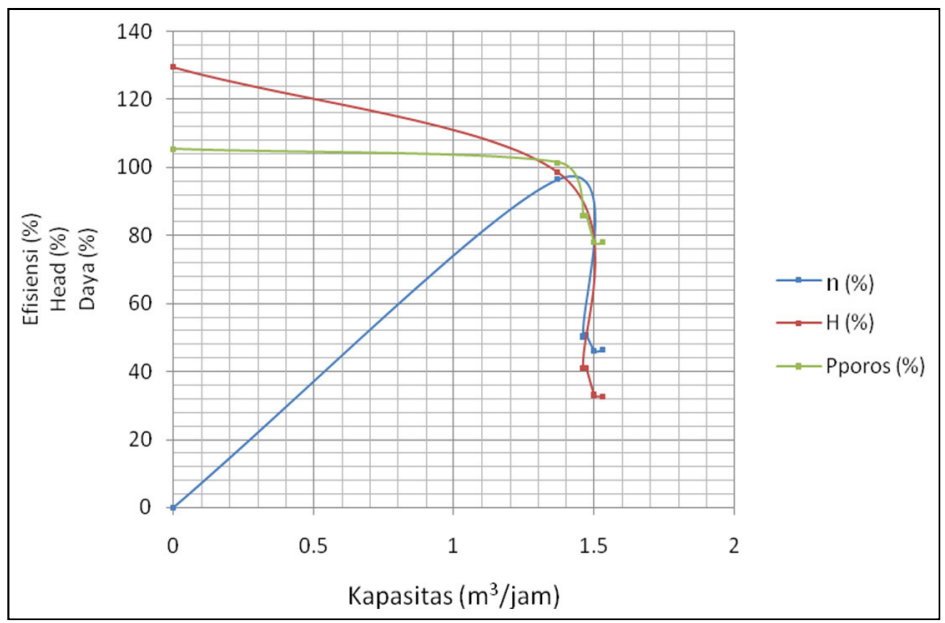

GAMBAR 2. Grafik antara efisiensi, daya pompa, head dengan kapasitas pompa pada putaran $1700 \mathrm{rpm}$

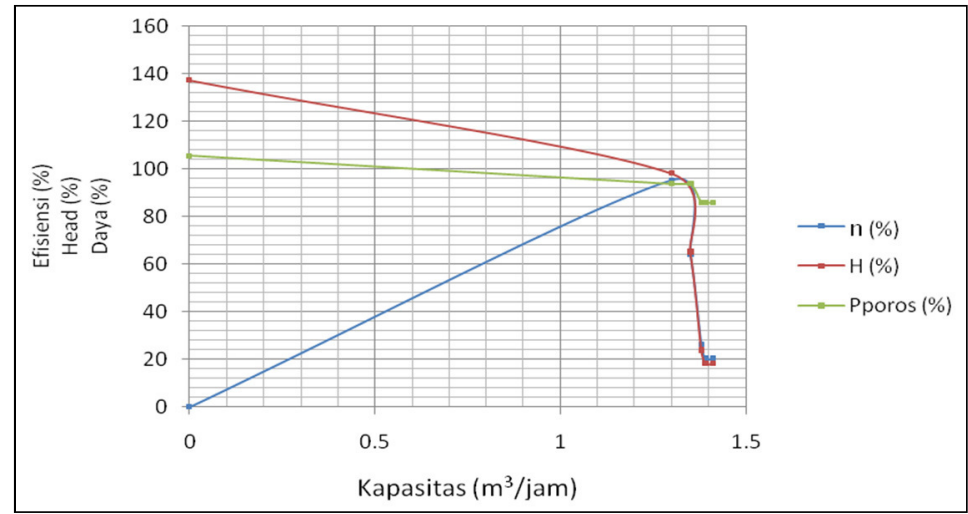

GAMBAR 3. Grafik antara efisiensi, daya pompa, head dengan kapasitas pompa pada putaran $1100 \mathrm{rpm}$.

Kurva karakterisasi pompa diberikan dalam bentuk grafik head, daya pompa dan efisiensi sebagai fungsi kapasitas aliran. Harga head, daya pompa dan efisiensi unjuk kerja pompa masing-masing dibagi dengan harga nominal spesifikasi pada titik kerja optimal dan diberikan dalam satuan persen (\%). Harga nominal spesifikasi teknik pompa roda gigi pada titik kerja operasionalnya diperlihatkan pada Gambar 1, saat putaran $2000 \mathrm{rpm}$ (pulley 1) berada pada kapasitas $1,35 \mathrm{~m}^{3} / \mathrm{jam}$ dengan daya poros pompa 283,02 watt dan head sebesar 88,69 m. Pada gambar 2 saat putaran $1700 \mathrm{rpm}$ (pulley 2) titik kerja operasional pompa berada pada kapasitas $1,37 \mathrm{~m}^{3} / \mathrm{jam}$ dengan daya poros pompa 294,34 watt dan head sebesar $88,6904 \mathrm{~m}$. Sedangkan pada gambar 3 saat putaran $1100 \mathrm{rpm}$ (pulley 3) titik kerja operasional pompa berada pada kapasitas $1,30 \mathrm{~m}^{3} / \mathrm{jam}$ dengan daya poros pompa 271,7 Watt dan head sebesar 83,29 $\mathrm{m}$. 
Dari ketiga Gambar kurva karakterisasi pompa diatas, didapat bahwa daya pompa mengalami penurunan karena terjadi slip antara pompa dengan motor pada sistem transmisi, getaran pada poros pompa dan panas pada pompa sehingga menimbulkan kerugian dalam operasi. Grafik Head mengalami penurunan karena semakin besar kapasitas pompa, tekanan pompa menjadi turun.

Untuk efisiensi hidrolik pada pompa roda gigi didapat bahwa semakin besar putaran pada poros pompa, maka efisiensi semakin meningkat. Efisiensi hidrolik untuk masing-masing putaran sebagai berikut untuk putaran $2000 \mathrm{rpm}$ efisiensi hidrolik 50,65\%, putaran $1700 \mathrm{rpm}$ efisiensi hidrolik 49,64\% dan putaran 1100 rpm efisiensi hidrolik 49,00\%.

Dari ketiga karakterisasi pompa diatas, didapat bahwa daya pompa mengalami penurunan karena terjadi slip antara pompa dengan motor pada sistem transmisi, getaran pada poros pompa dan panas pada pompa sehingga menimbulkan kerugian dalam operasi. Grafik Head mengalami penurunan karena semakin besar kapasitas pompa, tekanan pompa menjadi turun.

Nilai pompa roda gigi untuk head dan daya pompa adalah harga pada operasi nominal atau spesifikasi pompa roda gigi yang masing-masing adalah $90 \mathrm{~m}$ dan 1100 watt untuk kapasitas 1,1 $\mathrm{m}^{3} / \mathrm{s}$. Pembahasan dari hasil karakterisasi pompa roda gigi pada dapat dilihat pada tabel 9 .

TABEL 9. Head, Daya Pompa dan Efisiensi Pompa Roda Gigi Pada Kondisi Operasional.

\begin{tabular}{|c|c|c|c|c|}
\hline \multirow[b]{2}{*}{ Besaran Pompa } & \multirow{2}{*}{$\begin{array}{c}\text { Data } \\
\text { Spesifikasi }\end{array}$} & \multicolumn{3}{|c|}{ Data Aktual } \\
\hline & & $\begin{array}{c}\text { Pulley } 1 \\
\text { (2000 rpm) }\end{array}$ & $\begin{array}{c}\text { Pulley } 2 \\
\text { (1700 rpm) }\end{array}$ & $\begin{array}{c}\text { Pulley } 3 \\
\text { (1100 rpm) }\end{array}$ \\
\hline Kapasitas $\left(\mathrm{m}^{3} / \mathrm{s}\right)$ & 1,10 & 1,35 & 1,37 & 1,30 \\
\hline Head (m) & 90 & 88,69 & 88,69 & 83,29 \\
\hline Daya Pompa (watt) & 566 & 283,02 & 294,34 & 271,7 \\
\hline Efisiensi pompa (\%) & 80 & 98,4 & 96,4 & 95,2 \\
\hline Efisiensi mekanik (\%) & - & 51,45 & 51,45 & 51,45 \\
\hline Efisiensi hidrolik (\%) & - & 50,65 & 49,64 & 49,00 \\
\hline
\end{tabular}

Untuk efisiensi hidrolik pada pompa roda gigi didapat bahwa semakin besar putaran pada poros pompa, maka efisiensi semakin meningkat. Efisiensi hidrolik untuk masing-masing putaran sebagai berikut untuk putaran $2000 \mathrm{rpm}$ efisiensi hidrolik 50,65\%, putaran $1700 \mathrm{rpm}$ efisiensi hidrolik 49,64\% dan putaran $1100 \mathrm{rpm}$ efisiensi hidrolik 49,00\%.

\section{KESIMPULAN}

Dari hasil uji fungsi dan karakterisasi pompa roda gigi dapat diambil kesimpulan bahwa Komponen-komponen utama pada peralatan pengujian pompa roda gigi dapat berfungsi dengan baik. Meskipun ada sedikit kebocoran pada instalasi perpipaan tetapi masih dalam batas toleransi yaitu lebih rendah $5 \%$.

Efisiensi pompa semakin besar berbanding lurus dengan putaran pada pompa yaitu masingmasing, pada pulley 1 putaran $2000 \mathrm{rpm}$ sebesar 98,44\%, pulley 2 putaran $1700 \mathrm{rpm}$ sebesar $96,46 \%$ dan pulley 3 putaran $1100 \mathrm{rpm}$ sebesar 95,23\%. Peralatan pengujian pompa yang berhasil dibuat, dapat dipergunakan sebagai alat pengujian pompa, untuk memahami prinsip kerja dan mendapatkan karakteristik pompa roda gigi.

\section{DAFTAR PUSTAKA}

[1] Anis, Samsudin dan Karnowo. Dasar Pompa. Universitas Negeri Semarang. 2008.

[2] Berly, Jhon. Tugas Akhir Studi Karakterisasi Pompa Roda Gigi. Jakarta. 1997.

[3] Hartono, Sugi. Sistem Kontrol dan Pesawat Tenaga Hidrolik. Tarsito : Bandung. 1988

[4] Sularso dan Haruo Tahara. Pompa dan Kompresor. PT Pradnya Paramita : Jakarta. 2000.

[5] Suroso. Evaluasi Sistem Pendingin Reaktor Serba Guna GA. Siwabessy. BATAN. Jakarta. 2007. 